\title{
An Online Engagement Framework for Higher Education
}

\author{
Petrea Redmond, Lindy-Anne Abawi, Alice Brown, and Robyn Henderson \\ University of Southern Queensland
}

Amanda Heffernan

Monash University

\begin{abstract}
Student engagement is understood to be an important benchmark and indicator of the quality of the student experience for higher education; yet the term engagement continues to be elusive to define and it is interpreted in different ways in the literature. This paper firstly presents a short review of the literature regarding online engagement in the higher education environment, moving beyond discipline-specific engagement. It then presents a conceptual framework which builds upon recurring themes within the literature, including students' beliefs, attitudes, and behaviors. The framework was developed by adopting a constant comparison method to analyse the literature, and to search for and identify current and emerging themes. The framework identifies indicators for five key elements of online engagement, and the authors propose that the framework provides a guide for researchers and academics when exploring online engagement from a conceptual, practical and research basis. Finally, the paper provides recommendations for practice, outlining how the framework might be used to reflect critically upon the effectiveness of online courses and their ability to engage students.
\end{abstract}

Keywords: Online engagement, higher education, conceptual framework, distance education, student engagement

Redmond, P., Heffernan, A., Abawi, L., Brown, A., \& Henderson, R. (2018). An online engagement framework for higher education. Online Learning, 22(1), 183-204. doi:10.24059/olj.v22i1.1175

\section{An Online Engagement Framework for Higher Education}

This paper proposes a conceptual framework for online engagement. Student engagement in higher education has been an area highlighted consistently as having significant influence on student outcomes, including the successful completion of studies. Chen, Lambert, and Guidry (2010) suggested that student engagement in learning has a more significant impact on learning outcomes than who students are or where they enrol to study. As universities have increased their online presence and provided more opportunities for fully-online studies, student engagement in this mode requires further investigation and consideration. According to Coates (2009), student 
engagement research in the past has "devoted relatively little attention to online learning" (p. 66), a view supported by others (e.g., Robinson \& Hullinger, 2008), and Hampton and Pearce (2016) noted that being focused and engaged in course work as an online student is critical for success.

In addition, research has indicated that the majority of online learners are now non-traditional students who are balancing the competing demands of work, life, and study commitments and elect to study online for the convenience it offers (Chen, Lambert, \& Guidry, 2010; Thompson, Miller, \& Pomykal Franz, 2013). These external commitments and pressures have resulted in higher rates of student attrition (Meyer, 2014; Thompson et al., 2013) and, as such, online student engagement continues to be a pressing area for further exploration. Pittaway and Moss (2011) also raised the important theme of staff engagement, which "is essential before students can engage" (p. 141). This paper represents a form of staff engagement with these current and complex issues of teaching and learning.

A shift to online study requires adjustments to the teaching and learning practices traditionally associated with university learning environments. As Crampton, Ragusa, and Cavanagh (2012) highlighted, online environments are usually "characterised by different traditions, identities [and] expertise" (p. 2). Correlation has been found between students' grades and the resources accessed in online environments (Crampton et al., 2012), as well as the emotional and intellectual investment made by students when studying online (Pittaway \& Moss, 2014). These two aspects are thus important considerations for course design and pedagogy for lecturers seeking to maximise the engagement of online students.

With an awareness of the importance of notions of online engagement, and a lack of consensus or clarity about what this might look like, a group of education academics in a regional university in Queensland, Australia, came together to explore notions of student online engagement. The complex nature of fully-online education has been highlighted as an area requiring further attention (Pittaway \& Moss, 2011). This article contributes to this area of research by problematizing and rethinking the notion of student engagement in a higher education institution that has a long history of distance education and has moved strategically into online teaching and learning (Jones, Heffernan, \& Albion, 2015), with over $70 \%$ of students choosing to study online. Working in this context of change, the education academics started to consider what such change might mean for their understandings about student engagement. The paper, then, draws together themes and findings from relevant literature relating to online student engagement and proposes a conceptual framework to explore online student engagement in higher education. We are cognizant that others have produced conceptual frameworks about engagement (e.g., Coates, 2007; Lawson \& Lawson, 2013), but this one is different in that it draws on a systematic analysis of literature about the field, using the Framework Method of Gale, Heath, Cameron, Rashid, and Redwood (2013).

\section{Defining Online Engagement}

Engagement is a widely used term, but it appears to have a range of meanings and interpretations (Dixson, 2015; Lawson \& Lawson, 2013; Taylor \& Parsons, 2011). This is particularly the case in universities, where student engagement has become, according to Gibbs (2014), "one of the most ubiquitous buzzwords" (para 2). Gibbs argued that the term is "now used to refer to so many different things that it is difficult to keep track of what people are actually talking about" (para 2). Krause (2005) explained that student engagement is "a catch-all term most commonly used to describe a compendium of behaviours" (p. 3) that involve student learning. She 
defined it in terms of the "time, energy, and resources students devote to activities designed to enhance learning at university" (p. 3). Similarly, the Macquarie University Learning and Teaching Centre (2009) defined engagement as "the extent or quality with which students are committed and actively involved in their learning" (p. 1).

These definitions have emphasised individuals' engagement with learning rather than their interactions with staff or other students, even though such interaction has been identified as another key influencer of engagement (Chen, Lambert, \& Guidry, 2010). Aligned with this view is an expectation around staff engagement and the role of academics as facilitators of conversations. Fleckhammer and Wise (2011) noted that "online students ... need to be able to engage with their learning in an independent style, but it may be that overall academic engagement can be facilitated for this cohort by developing a greater sense of social engagement" (p. 393). As Coates (2006) explained, social relationships are important, alongside academic engagement. This ties in with the work of Kift (2004) and Rhodes and Nevill (2004), who indicated that engagement is affected by student experience and transitions which have implications for the pedagogical practices taken by faculty members in online learning environments.

These multiple conceptualisations of engagement have resulted in diverse views about what engagement is and about the place and interconnectedness of cognitive, socio-cultural, affective, behavioral, ecological and organizational factors and even the actions of students as a collective (Kahn, Everington, Kelm, Reid, \& Watkins, 2017; Lawson \& Lawson, 2013; Reeve \& Tseng, 2011). The importance of these connections and the implications for practice are evidenced by their inclusion in the conceptual framework for engagement presented in this paper. The literature presents a picture of students who choose to study online and reflects the need for faculty to foster learning environments where traditional teacher-student and student-student interactions can be translated into online study, due to the common needs and aspirations of online learners. As Coates (2006) highlighted, "institutions are responsible for creating environments that make learning possible, that afford opportunities to learn," but "the final responsibility for learning ... rests with students" (p. 29).

\section{Online Student Demographics and Needs}

Findings from the literature (e.g., Oblinger, 2003; Krause, 2006) have indicated that university students who choose to study online are inclined to do so because it provides flexibility, enabling them to balance external commitments with their studies. Nevertheless, study sometimes "runs the risk of simply becoming another appointment or engagement in the daily diary, along with paid work and a range of other commitments beyond the campus" (Krause, 2006, p. 3). Since online learners tend to be non-traditional students and are often adult learners who face competing demands, including family and work responsibilities, this can result in challenges to their ability to "work within the routine of a typical classroom" (Scheg, 2014, p. 8). Studies have highlighted that employment, childcare options, and financial constraints can have an impact on students' decisions whether to study online or face-to-face (Chen et al., 2010; Thompson et al., 2013), and these same factors can have an impact on their ability to succeed.

Although online learning provides an opportunity for non-traditional students to achieve their educational goals or aspirations while balancing these complex demands, some studies have suggested that the external demands sometimes pose challenges that make it difficult to prioritise study (Thompson et al., 2013). Chen et al. (2010), therefore, emphasised the importance of ensuring quality in programs and pedagogy so that online students receive the same level of 
support as face-to-face students, cautioning that a tiered system of educational segregation could potentially result if this was not consciously addressed. This is particularly important given the disproportionate number of minority, part-time, and working-class students who elect to study online (Chen et al., 2010). Support for students is therefore vital to ensure student engagement and positive learning outcomes from study. As such, it is necessary to further explore what the literature highlights as key principles of student engagement in online learning.

\section{Engagement in Online Higher Education}

The literature on engagement reinforces its importance in online teaching and learning, although Bowen (2005) suggested that there is a lack of consensus about what engagement means in practice. Although much of the literature related to online engagement incorporates the three key areas of behavioral, emotional, and cognitive engagement (Fredericks, Blumenfeld, \& Paris, 2004; Reeve \& Tseng, 2011) as they affect students' attitudes and motivations, Lawson and Lawson (2013) suggest that there is a need for a "more nuanced and less formulaic conception of student engagement" (p. 433). In doing that, we emphasise the clear distinction between traditional face-to-face learning environments and online learning environments and posit that the shift of higher education institutions to online presents challenges for course design and pedagogical practice.

We propose an interdisciplinary conceptual framework designed specifically for reflecting on online student engagement in higher education, using categories drawn from the themes within the literature base. We now explain the methodology that was used, before presenting the framework and a discussion of the literature and thinking that informed its construction.

\section{Methods}

The proposed conceptual framework is grounded in a social constructionist approach (Mallon, 2013), combined with deductive thematic analysis for the specific purpose of creating an evaluative framework to explore online learning-based practices linked to student engagement. As noted by Bradley, Curry, and Devers (2007), a deductive analysis allows "new inquiries to benefit from and build on previous insights in the field" (p. 1763), but it does not preclude new categories. Social constructionism endorses a subjectivist view of knowledge where knowledge is outcome of social interchange (Guterman, 2006). A useful way of thinking about social construction is that it has two parts: "X socially constructs Y" (Mallon, 2013, para 4). In this paper, for example, a group of researchers (Xs) worked together as agents for the filtering and adaption of existing knowledge and the inputting of additional contextual and experiential knowledge in order to co-construct a knowledge or conceptual framework (Y), based on agreed categories or themes.

Social scientists use a number of terms to describe themes within their data, for example, categories, codes, labels, thematic units, and concepts (Ryan \& Bernard, 2003). In the health sciences, a recently developed method for the management and analysis of qualitative data is the Framework Method (Gale et al., 2013). This method uses identifiers such as analytic memos, categories, codes, indexes and themes to organise and then analyse broad types of data. The Framework Method is not aligned to any one epistemological stance, but instead it is a flexible tool that can be adapted for any qualitative generation of themes. It has been used largely to explore transcripts from interviews or focus groups, but it may, "in principle, be adapted for other types of textual data, including documents ... or field notes from observations” (Gale et al., 2013, p. 2). 
As the authors of the Framework Method (Gale et al., 2013) indicated, those using the method need to consider whether and why the framework might be useful to a particular situation. In the case of the current examination of literature about student engagement in online learning, the framework offered a way of accommodating varied data that were related to "similar topics" (Gale et al., 2013, p. 2). Thus, the framework offered a way of systematically categorizing data and generating descriptions and explanations.

With this in mind, the Framework Method (Gale et al., 2013) was adapted and used to develop a conceptual framework, with the intent that further data collation and analysis would be undertaken by the researchers. This will be done by using the framework that is developed and documenting analytic memos and observations of practices related to a range of teacher education courses within the authors' institution of higher education.

To commence the creation of the initial framework, the key concepts and indicators from existing research about engaging online learners were collated using an a priori approach. The literature was explored, and each researcher used a constant comparison method to collate both current and emerging themes. Although often associated with grounded theory, constant comparison is a useful method for theme identification from any text (Leech \& Onwuegbuzie, 2007). The researchers individually and then collectively used a deductive approach to filter concepts, indicators, categories, and implications from the literature and identify additional themes that were then superimposed over the existing ones.

This process ensured that individual interpretations of the literature were discussed and collectively explored in detail before completing the deductive process of determining the final themes. It acknowledged the work done by others in the field, as well adding insight with new shared understandings prior to the construction of the framework. A three-phase filtering process was then employed to: a) ensure shared understandings of what was meant by the terms used within the framework; b) guarantee that the wording was succinct and relevant; and, c) provide assurance of future usability and broad applicability. Figure 1 provides an overview of the deductive process that was used.

The resulting framework and process were then shared with national and international experts in online teaching and learning and feedback was requested and received. Final refinements were then made according to this feedback. Figure 2 lists the six-stage process that was used to develop the framework. 


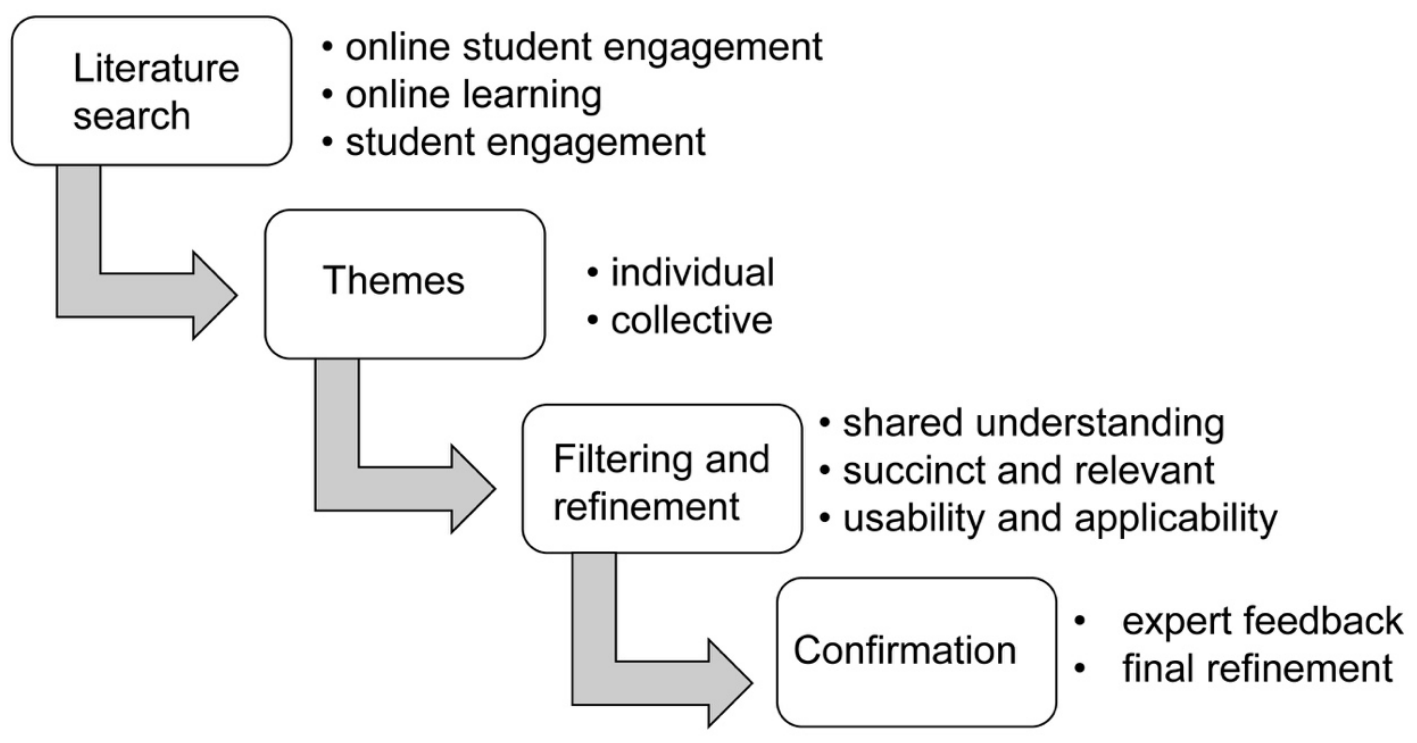

Figure 1. The Deductive Process
Stage 1: Each researcher explored the literature to come up with a first take on the related themes according to common terms or ideas until these became repetitive and no new ideas emerged.

Stage 2: Three researchers worked together to filter these into related groups of ideas and then to refine theme terminology.

Stage 3: The whole team further refined elements and indicators according to the shared understandings.

Stage 4: An initial framework was created.

Stage 5: Expert feedback was requested from six national and international experts deemed as authorities on online teaching and learning.

Stage 6: Adjustments were then made according to the feedback received.

$$
\text { Figure 2. The Six-Stage Process for Framework Development }
$$

\section{Proposed Conceptual Framework for Online Engagement}

Internationally, survey instruments have been developed to measure student engagement in higher education. The surveys all build on the initial instrument, the National Survey of Student Engagement (NSSE) developed in the United States (The Trustees of Indiana University, 2016), and also used in Canada. Australia has the Australasian Survey of Student Engagement (AUSSE) (Australian Council for Educational Research, n.d.), also used by New Zealand, and the Student Experience Survey (SES), part of the Quality Indicators for Learning and Teaching (QiLT) (Australian Government Department of Education and Training, 2015, 2016a, 2016b), whilst the United Kingdom uses the United Kingdom Engagement Survey (UKES) (Higher Education Academy, 2015). 
Allen, Seaman, Poulin, and Straut (2016) have been tracking online education in the United States for 13 years. In their 2015 report, they found that $29 \%$ of higher education students take at least one distance course and that this number was growing. At the regional university where the current research took place, $70 \%$ of the students were studying externally or online. Meyer (2014) identified that "achieving student engagement in online courses may be more important than it is in on-campus courses because online students have fewer ways to be engaged with the institution and perhaps greater demands on their time and attention as well" (p. 1). With such a large number of students embarking on higher education study without traditional face-to-face supports, it is essential to understand how to improve teaching and learning for enhanced online engagement. Krause and Coates (2008) have called for "a more robust theorising of the engagement concept that encompasses both quantitative and qualitative measures" (p. 493).

In response to this challenge, the authors propose a way of understanding the various types of engagement that work together to connect students with learning. The literature (Pittaway, 2012; Weimer, 2016) speaks to a number of elements of engagement which may be defined separately but are interconnected in practice because, as Weimer (2016) reminded us, engagement is a "multidimensional construct" (para 7).

Many past explorations around face-to-face engagement have been limited to three major types of engagement: behavioral, emotional and cognitive. Our overview of engagement, as seen in Figure 3, provides a detailed approach to exploring engagement within online environments. The figure presents five elements of engagement for teaching and learning in the online space: social engagement, cognitive engagement, behavioral engagement, collaborative engagement, and emotional engagement. These five elements are considered crucial for effective student engagement within the online learning and teaching environment. That is not to say that these same elements do not also have a place when investigating face-to-face learning or more traditional distance learning contexts.

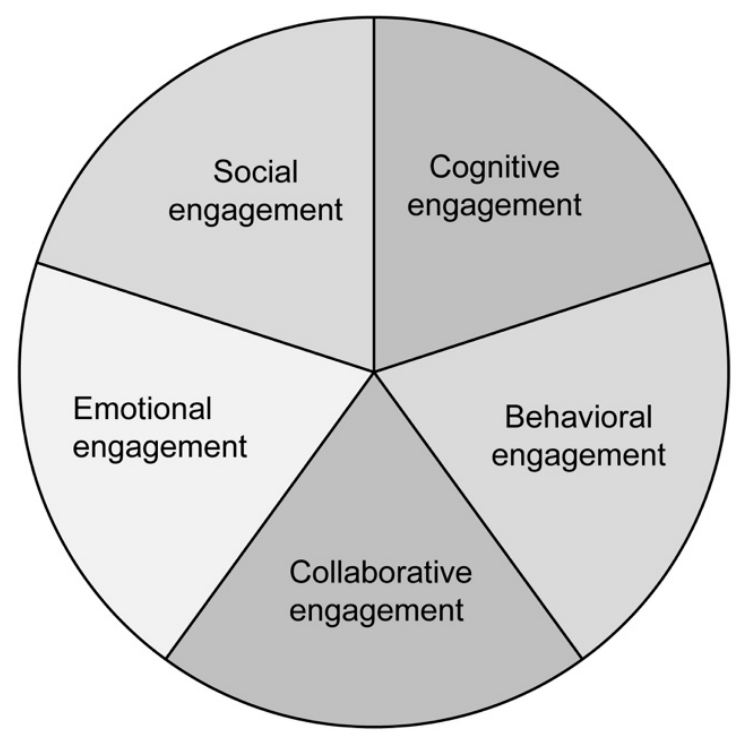

Figure 3. Online Engagement Framework Overview 
The authors posit that the online engagement framework presented here is a multidimensional construct with interrelated elements that impact on student engagement in online settings. The framework can be utilised by academics to reflect upon the learning engagement within their online courses and the implications for personal teaching practice as well as course and, ultimately, program design.

The online engagement framework for higher education presented in Table 1 provides a summary of the elements and the indicators for each element. The framework has emerged from a social constructionist perspective in higher education where asynchronous and synchronous group discussions occur as an intentional way to promote individual and group learning. It is not hierarchical or linear in nature, nor is each element meant to be explored as an isolated process. Rather, the framework provides a tool to unpack the dynamic nature of online engagement.

\begin{tabular}{|l|l|}
\hline Online Engagement Element & Indicators (illustrative only) \\
\hline Social engagement & $\begin{array}{l}\text { Building community } \\
\text { Creating a sense of belonging } \\
\text { Developing relationships } \\
\text { Establishing trust }\end{array}$ \\
\hline Cognitive engagement & Thinking critically \\
& Activating metacognition \\
& Integrating ideas \\
& Justifying decisions \\
& Developing deep discipline understandings \\
& Distributing expertise \\
\hline Behavioral engagement & Developing academic skills \\
& Identifying opportunities and challenges \\
& Developing multidisciplinary skills \\
& Developing agency \\
& Upholding online learning norms \\
& Supporting and encouraging peers \\
\hline Collaborative engagement & Learning with peers \\
& Relating to faculty members \\
& Connecting to institutional opportunities \\
& Developing professional networks \\
\hline \multirow{2}{*}{ Emotional engagement } & Managing expectations \\
& Articulating assumptions \\
& Recognising motivations \\
& Committing to learning \\
\hline
\end{tabular}

Table 1. Online Engagement Framework for Higher Education

As explained, the online engagement framework is intended to propose a theoretical view of student engagement that builds on related literature and the filtering of literature themes into key concepts. The five interrelated elements provide a tool for instructors, instructional designers, and researchers to facilitate and evaluate online student engagement. Each element of the framework, and the related literature, along with indicators, are discussed in detail below. Note that the indicators are illustrative only and are not meant to be a definitive list. 


\section{Social Engagement}

\section{Results}

Social engagement refers to "students" social investment in the collegiate experience" (Knight, 2013, p. 73). It includes participation in academic as well as non-academic activities which occur outside the virtual classroom, such as recreation or social functions, along with discussions of a social nature (Coates, 2006). It is a way of creating purposeful relationships with others. In an online environment, social interactions are often in the form of students talking about themselves and their contexts; they may result in ongoing interactions through social media. According to Krause (2005), "opportunities for social engagement are equally as important as intellectual pursuits" (p. 9). Social engagement is certainly of key importance when students are required to work with peers for assessment and/or learning tasks and it is related to socialemotional buy-in as well as social interactions (Sinha, Rogat, Adams-Wiggins, \& Hmelo-Silver, 2015).

The literature also refers to concepts such as relational engagement (Billet, 2008) and social presence (Garrison, Anderson, \& Archer, 2000), which are related to social engagement. Table 2 presents a summary of the literature and the indicators for the social engagement element.

\begin{tabular}{|l|l|}
\hline Online Engagement Element & Indicators (illustrative only) \\
\hline Social engagement & Building community \\
(Billet, 2008; Chen, Lambert, \& Guidry, 2010; & Creating a sense of belonging \\
Cheng, Liang \& Tsai, 2013; Dennen, 2008; & Developing relationships \\
Garrison, Anderson, \& Archer, 2000; Knight, & Establishing trust \\
2013; Krause, 2005; Pittaway \& Moss, 2014; & \\
Australian Government Department of & \\
Education and Training, 2016a); Sinha, Rogat, & \\
Adams-Wiggins, \& Hmelo-Silver, 2015; & \\
Wright, Jones, \& D'Alba, 2013) & \\
\hline
\end{tabular}

Table 2. Indicators for Social Engagement

Social engagement in an online environment can be illustrated through actions that build community such as social forums and the use of open communication platforms. It includes the development of relationships with peers and instructors, whether via friendships and interactions beyond study requirements or effective working and studying relationships. Informal or social engagement opportunities with instructors are important for students' learning, both online and face-to-face (Chen, Lambert, \& Guidry, 2010). Social engagement involves building rapport, respect, and trust to create a sense of belonging and group cohesion within a learning community (Sinha, Rogat, Adams-Wiggins, \& Hmelo-Silver, 2015; Wright, Jones, \& D’Alba, 2013).

\section{Cognitive Engagement}

Cognitive engagement is the active process of learning. Bowen (2005) stated that this type of engagement is the most fundamental form of engagement. This was supported by Fredricks, Blumenfeld, and Paris (2004) who identified cognitive engagement as students engaged in the learning process to "comprehend complex ideas and master difficult skills" (p. 60). It is related to 
what students do and think to promote learning. Bowen (2005) continued by referring to the process as students "paying attention to the learning" and becoming "engaged learners" (p. 5). In the literature, it is not clearly defined and is often linked with concepts such as motivation to learn, values and beliefs, metacognition and self-regulation, and strategy use and effort (Fredricks, Blumenfeld, \& Paris, 2004; Greene, 2015).

There are different levels of cognition, normally referred to as deep and surface (Fredricks, Blumenfeld, \& Paris, 2004; Henri, 1992). In the online space, surface cognitive engagement would be contributions that offer solutions without judgement or justification; repeating ideas without clarification; or general agreement with others without explanation or further contribution. Students who work at this level can easily be distracted, employ avoidance strategies, and focus on completing the task as a means to an end rather than learning from the task (Fredricks, Blumenfeld, \& Paris, 2004). Those students who display deep cognitive engagement demonstrate more complex processes. Their online posts justify or compare ideas and solutions; they integrate ideas from multiple sources, provide new information, judgements, or integration of information, and can support their ideas (Henri, 1992). Learners working at deep cognitive levels have a psychological investment in learning, a preference towards challenge, as well as a desire to go beyond base requirements. They sustain engagement through persistence and can find relevance in new information by aligning it with previous knowledge. Instructors can impact the level of cognitive engagement based on the requirements of activities and assessment tasks.

Other terms which align with the element of cognitive engagement are disciplinary engagement (Hickey, Quick, \& Shen, 2015), intellectual engagement (Pittaway \& Moss, 2014), academic challenge (Center for Postsecondary Research, Indiana University School of Education, 2016), and cognitive presence (Garrison, Anderson, \& Archer, 2000).

\begin{tabular}{|l|l|}
\hline Online Engagement Element & Indicators (illustrative only) \\
\hline Cognitive engagement & Thinking critically \\
(Center for Postsecondary Research, Indiana & Activating metacognition \\
University School of Education, 2016; Coates, & Integrating ideas \\
2009; Engle \& Conant, 2002; Fredricks, & Justifying decisions \\
Blumenfeld, \& Paris, 2004; Garrison, & Developing deep discipline \\
Anderson, \& Archer, 2000; Greene, 2015; & understandings \\
Hickery, Quick, \& Shen, 2015; Meyer, 2014; & Distributing expertise \\
Petty \& Farinde, 2013; Pittaway \& Moss, 2014; & \\
Redmond, 2014; Reeve \& Tseng, 2011; & \\
Weimer, 2016) & \\
\hline
\end{tabular}

Table 3. Indicators for Cognitive Engagement

Bowen (2005) pointed out that "as students attempt to reconcile what they learn with what they previously believed, they demonstrate growth in understanding, values, and commitment typical of mature cognitive development" (p. 5). This might also be known as the acceptance or embracing of cognitive dissonance. Learners who are deeply cognitively engaged self-regulate or "use metacognitive strategies to plan, monitor, and evaluate their cognition when accomplishing tasks" (Fredricks, Blumenfeld, \& Paris, 2004, p. 64). 
High levels of cognitive engagement do not occur outside of a particular context. They always occur in a discipline context. However, the strategies students use for cognitive engagement, such as critical thinking, metacognition, integration, and justification, are multidisciplinary and can be used in any learning situation. Learning that is discipline-specific, such as developing deep discipline-specific conceptual understandings, discipline-specific metalanguage, and discipline expertise change as students move from one discipline to another.

\section{Behavioral Engagement}

In their investigation of engagement, Fredricks, Blumenfeld, and Paris (2004) found three dimensions of positive behavioral engagement. First, positive behaviors such as adhering to rules and norms, asking questions, contributing to discussions, and paying attention; second, active participation in academic activities; and third, participation in extracurricular or non-academic activities within the educational institution. In the end, however, they described behavioral engagement as "doing the work and following the rules" (p. 65).

Behavioral engagement is also referred to in the literature with terms such as academic engagement (Pittaway \& Moss, 2014; Young, 2010), agency engagement (Reeve \& Tseng, 2011), learning presence (Shea et al., 2012), self-regulating behaviors (Cheng, Liang, \& Tsai, 2013), skills engagement (Handelsman, Briggs, Sullivan, \& Towler, 2005), and verbal and nonverbal attentiveness (Weimer, 2016). The indicators for the behavioral element of online engagement are provided in Table 4.

\begin{tabular}{|l|l|}
\hline Online Engagement Element & Indicators (illustrative only) \\
\hline Behavioral engagement & Developing academic skills \\
(Cheng, Liang, \& Tsai, 2013; Coates, & Identifying opportunities and challenges \\
2009; Fredricks, Blumenfeld, \& Paris, & Developing multidisciplinary skills \\
2004; Handelsman, Briggs, Sullivan, \& & Developing agency \\
Towler, 2005; Meyer, 2014; Center for & Upholding online learning norms \\
Postsecondary Research, Indiana & Supporting and encouraging peers \\
University School of Education, 2016; & \\
Petty \& Farinde, 2013; Pittaway \& Moss, & \\
2014; Reeve \& Tseng, 2011; Shea et al., & \\
$2012 ;$ Weimer, 2016) & \\
\hline
\end{tabular}

Table 4. Indicators for Behavioral Engagement

Students who are behaviorally engaged "are characterized by [their] positive conduct, class participation, involvement in the learning task, high effort and persistence, positive attitudes, and self-regulation of their learning" (Young, 2010, p. 2). They also support and encourage their peers to follow procedures, actively participate in the learning process, reduce disruptive behaviors and complete academic tasks (Fredricks, Blumenfeld, \& Paris, 2004). Students who are behaviorally engaged communicate interest in learning and find personal relevance; they also seek help when required and provide assistance to others. 
In addition to these learning behaviors students develop academic skills which contribute to their successful learning outcomes. These include skills such as academic reading, writing and listening, planning, time management, and goal setting (Pittaway \& Moss, 2014).

\section{Collaborative Engagement}

Collaborative engagement is related to the development of different relationships and networks that support learning, including collaboration with peers, instructors, industry, and the educational institution. The concepts of social and emotional engagement indicate that connecting with others for both educational and non-educational activities is beneficial from an academic, social, and emotional perspective.

Similar concepts discussed in the literature include professional engagement (Pittaway \& Moss, 2014); learning with peers (Center for Postsecondary Research, Indiana University School of Education, 2016), experiences with faculty (Center for Postsecondary Research, Indiana University School of Education, 2016), enriching educational experience (Meyer, 2014), and campus environment (Center for Postsecondary Research, Indiana University School of Education, 2016).

\begin{tabular}{|c|c|}
\hline Online Engagement Element & Indicators (illustrative only) \\
\hline $\begin{array}{l}\text { Collaborative engagement } \\
\text { (Center for Postsecondary Research, Indiana } \\
\text { University School of Education, 2016; } \\
\text { Coates, 2009; Dennen, 2008; Meyer, 2014; } \\
\text { Pittaway \& Moss, 2014; Australian } \\
\text { Government Department of Education and } \\
\text { Training, 2016a; Reeve \& Tseng, 2011) }\end{array}$ & $\begin{array}{l}\text { Learning with peers } \\
\text { Relating to faculty members } \\
\text { Connecting to institutional } \\
\text { opportunities } \\
\text { Developing professional networks }\end{array}$ \\
\hline
\end{tabular}

Table 5. Indicators for Collaborative Engagement

Collaboration with peers is related to engagement for academically worthwhile purposes, for example, discussion, tutoring, study groups, and group tasks or assessment. Students studying online are more likely to have to collaborate online because they are less likely to be located geographically near peers.

Collaborative engagement with faculty and the institution is largely related to the development of supportive learning environments. From an academic perspective, instructors regularly establish a requirement for collaborative engagement through the use of group or team activities and assessment.

Engagement with peers and professionals in industry is often related to establishing personal and professional learning networks (Albion, 2014). Both can be useful for entry into a profession, to assist continuing professional learning, and to ensure sustained industry relevance and currency. Engagement with industry is more critical in programs that are aligned with specific professions (Pittaway \& Moss, 2014). 


\section{Emotional Engagement}

Emotional engagement refers to students' emotional reaction to learning. It is related to their feelings or attitudes towards learning and can be attributed to the affective or emotional component of engagement. Sinatra, Heddy, and Lombardi (2015) reported that "both negative and positive emotions can facilitate activation of attention and engagement" (p. 2). It includes emotional reactions to people in the educational context such as peers and teachers, or to the educational institution itself, the subject matter or discipline, or the tasks that students are expected to do. In summary, emotional engagement includes "interest, values, and emotions" (Fredricks, Blumenfeld, \& Paris, 2004, p. 65).

Other terms found in the literature to discuss this type of engagement include personal engagement (Pittaway, 2012), emotional presence (Cleveland-Innes \& Campbell, 2012), affective reactions (Fredricks, Blumenfeld, \& Paris, 2004), and psychological engagement (Vogt, 2016). Cleveland-Innes and Campbell (2012) stated that "emotion is identified as important to student adjustment to the role of online learner" (p. 272), and online instructors should determine how best to harness emotion for effective learning and teaching.

\begin{tabular}{|l|l|}
\hline Element & Indicators (illustrative only) \\
\hline $\begin{array}{l}\text { Emotional engagement } \\
\text { (Cleveland-Innes, \& Campbell, 2012; Fredricks, }\end{array}$ & Managing expectations \\
Blumenfeld, \& Paris, 2004; Meyer, 2014; Petty & Recognizing motivations \\
\& Farinde, 2013; Pittaway, 2012; Pittaway \& & Committing to learning \\
Moss, 2014; Reeve \& Tseng, 2011; Vogt, 2016; & \\
Weimer, 2016) & \\
\hline
\end{tabular}

Table 6. Indicators for Emotional Engagement

From a review of the literature, the authors provide four indicators which exemplify emotional engagement, as seen in Table 6: managing expectations, articulating assumptions, recognizing motivations, and committing to learning. Students' emotional engagement can be observed through their attitude, enthusiasm, interest, anxiety or enjoyment in the learning process. Positive emotional engagement would be displayed by students who value learning or the acquisition of knowledge and skills and appreciate success.

\section{Discussion}

Although the literature points to the value of employing student engagement techniques in online learning to increase student engagement, which in turn translates to producing a better quality of graduate (Meyer, 2014; Teacher Education Ministerial Advisory Group, 2014), there is still confusion in terms of "what counts" as online engagement (Bowen, 2005), what this might look like in practice, and the types of approaches that might be employed. Researchers such as Pittaway and Moss (2011) suggested that before students engage it is essential that staff adopt engagement practices. However, although the number of higher education students studying online and taking online courses continues to grow (Allen, Seaman, Poulin, \& Straut, 2016), there are still gaps in the research, literature, and models to guide academic practice, including the 
complexities linked to online learning and strategies to support engagement. In this paper, the authors have drawn from, and reflected on, the existing body of literature, problematized the notion of student online engagement, and contributed to new understandings of online engagement. This has resulted in the construction of an Online Engagement Framework for Higher Education.

Although the authors of this paper do not claim to offer a panacea for curing all the difficulties and ambiguities associated with online engagement, we nevertheless offer a robust framework that others (including instructors, instructional designers, course teams, program coordinators, policy advisors, advisory groups, and researchers) may find of value as a point of reference, particularly in helping to reflect upon their respective decision-making processes prior to and during the process of supporting the student online learning journey. We hope the framework also serves as an audit and reflection tool, to think about, inform, and perhaps even challenge others to critically consider the types of strategies they employ for facilitating different types of online engagement within their contexts. This process, utilising the framework offered here, will hopefully prove to be invaluable in assisting critical reflection about online engagement from a range of different lenses and pedagogical positions.

Furthermore, the authors of this paper are aware of the complexity and variation in learning environments and contexts in which educators and students are positioned. Therefore, the worth that others will ascribe to the online engagement framework will be dependent on a range of elements and contextual factors. As a final intended contribution of this paper within the field of online learning and engagement, the authors offer a number of recommendations. These are targeted to different audiences, with the common denominators of thinking about and employing strategies to support online learning engagement. We hope that readers will find value in these suggestions, particularly in seeing relevance and application when moving through the process of deploying the framework in teaching practice. These points are offered only as a potential guide to assist in the consideration of opportunities for clarifying and perhaps "thinking otherwise" about online engagement in the multiple forms in which it is understood. Our ultimate goal is to build capacity for supporting and enhancing online students' learning journeys.

\section{Instructors: A Lens to Plan Teaching and Learning}

With so many students now moving to online learning (Chen, Lambert, \& Guidry, 2010; Thompson et al., 2013) and courses increasingly now offered online, the Online Engagement Framework for Higher Education offers instructors a lens for planning teaching and learning. This includes employing the online engagement framework as an audit tool, or point of reference, when considering the types of engagement currently demonstrated by students, and the relevant indicators of the various elements of the framework. The use of the framework will enable instructors to consider whether some forms of engagement might be privileged, and whether other forms of engagement need to be utilised more often to heighten engagement, and therefore to enhance student learning. The online engagement framework may also help to confirm the elements of engagement currently employed in teaching and learning practices that are identified as a best fit for the intended learning outcomes of a course. However, as Bower (2001) pointed out, instructors may be challenged to adjust their current pedagogical practices or may even resist any suggestion of change to practice.

The online engagement framework also offers instructors an opportunity to think more deeply about the associated indicators of engagement: to think about how engagement might look in relation to better supporting the diversity of students engaging in online study, as well as about 
the types of engagement strategies that would enable the stories and voices of students to be heard. The framework offers a reference point for thinking about the elements and types of engagement that might better afford opportunities for students to share the richness of their backgrounds, experiences, and understandings with others. It also asks us, as faculty, to think about elements and types of engagement that afford students opportunities to learn from and with others, and to think about the types of engagement that provide equitable and effective learning and teaching opportunities for all students.

\section{Instructional Designers: Assisting Instructors to Plan for Active Engagement}

The online engagement framework also offers instructional designers a framework to share, as well as a guide for assisting instructors to reflect upon and plan for activities and conditions which enhance active online engagement (Coates, 2009). This might include instructional designers and institutional learning and teaching facilitators referring instructors to the extensive discussion and related literature that unpacks each of the five online engagement framework elements. Targeted suggestions could also be offered regarding ways to design courses and learning experiences that integrate specific indicators to enhance and facilitate online learning and engagement for students.

With the theme of social engagement and connectedness particularly prevalent in a range of engagement frameworks (Australian Government Department of Education and Training, 2016a; Cheng, Liang, \& Tsai, 2013; Dennen, 2008; Garrison, Anderson, \& Archer, 2000; Pittaway \& Moss, 2014), and the value students place on levels of instructor and classmate interaction (Gerhardt, 2016), instructional designers may wish to use the online engagement framework to highlight the associated indicators or processes that effectively support the element of social engagement. As such, the online engagement framework may be utilised as a tool to raise awareness and build capacity with instructors in relation to the elements and indicators of engagement.

\section{Teaching Teams: A Tool for Critical Reflection}

As part of a teaching teams' annual course review, and as part of completing the cycle of moderation, the online engagement framework offers academics a tool for critical reflection, through auditing the types of engagement employed in their courses. Teams could also reflect critically on the effectiveness of each of the approaches in addressing and supporting the student learning journey and course learning objectives. As research indicates that strategies employed to support student engagement are contextual in relation to factors such as the student cohort, the course, and the course content (Lawrence, Dashwood, Burton, \& Brown, 2013), the online engagement framework offers teaching teams a valuable reference point for considering the "best fit" of engagement indicators for the types of learning and the students in their courses.

Teaching teams may wish to adopt a pragmatic approach of making better use of learning analytics to monitor, better understand, and evaluate levels of student engagement, again using the online engagement framework as a reference point. This in turn will help inform future course offerings, approaches, course materials, and pedagogical practices. For example, in reviewing learning analytics, it might be identified that some students who missed online classes or scheduled chat sessions did not access the recordings or transcripts of these sessions and did not access the discussion boards or emails (Thompson et al., 2013). As part of a course team review, instructors may choose to explore engagement options to better support these particular students and foster motivation and engagement in the future. They may also wish to utilise the indicators of the online 
engagement framework to help inform future course design and pedagogical practice and with the aim of facilitating higher levels of academic engagement and motivation for online students.

\section{Program Level: A Review Across Courses}

At a broader programmatic level, and for those instructors whose role is associated with program or institutional teaching and learning, the online engagement framework offers a tool for auditing the types of engagement employed across a program. Such a process could provide insight into which elements and processes are privileged, popular, and utilised, as well as identify which elements may not have much exposure. This in turn could provoke robust professional and pedagogical conversations and questions with program teams, in relation to the visible trends, and the impact of not employing other engagement indicators and elements.

At a program level, the online engagement framework offers a way of challenging existing discourse and introducing alternative discourse about understandings of engagement, as well as processes and strategies that support quality and effective student engagement. Drawing upon the online engagement framework as an interdisciplinary frame and reference point, program teams may be better able to respond proactively to government reports and public discussions. The framework could be used to explain and clarify the elements, strategies, and pedagogies employed by institutions to support learning and teaching that enhance student engagement.

\section{Macro Level: A Reference Point to Inform Interpretations and Benchmarking of Engagement}

Finally, the authors suggest that the online engagement framework can potentially provide professionals involved in determining quality indicators for learning and teaching (see Australian Government Department of Education and Training, 2016a, 2016b), policy advisors and advisory groups with a reference point to inform the structuring and thinking behind institutional and systemic tools that seek to categorise engagement, student satisfaction, and other forms and measurements. For example, the online engagement framework could help to inform and frame future higher education learning and teaching surveys, by adopting a more comprehensive interpretation and lens for determining learner engagement in the online environment. This would help to widen the lens beyond the current narrow view of engagement, which is limited to exploring an aspect such as "interactions among students and teaching staff" (Australian Government Department of Education and Training, 2016b). A spinoff of this might be a shift in the public's perception of reports and reviews regarding the indicators of quality teaching and learning in higher education.

With a plethora of studies and research reporting on teaching and learning in higher education, it is hoped that researchers who in the future might wish to investigate the types and levels of online engagement might refer to and draw upon the elements of engagement and the associated discussion outlined in this paper. This would foster consideration and thinking about how online engagement is understood, and where it might be evidenced in practice. Researchers may wish to use the online engagement framework to problematize understandings of online student engagement. The elements of the online engagement framework may provide useful categories for investigating the types of engagement that are privileged and the barriers to employing other types of engagement in particular contexts.

\section{Next Steps}

Future research surrounding the Online Engagement Framework for Higher Education is expected to take place in four phases. First, the framework is yet to be statistically validated. 
Although the framework has been developed from the literature and the research team has sought feedback from experts in the field, it is critical to determine the reliability and validity of the framework. A second phase to this research is for the research team to use the framework as a lens to unpack the engagement within their own courses.

The third phase is to work with students to reflect upon the framework and to have them determine how it might help their studies and how it might assist them to unpack their actual levels of engagement in their online studies. Finally, the framework should be explored by academics in different disciplines and other universities to see if it is valid in a range of different contexts. We invite other instructors and researchers to use the framework across various populations and disciplines to assist in the validation of the online engagement framework and to comment on its robustness.

\section{Conclusion}

The goal of this research was to develop an Online Engagement Framework for Higher Education. The framework was developed from a review of the relevant literature that explores engagement in educational contexts. The framework that was developed includes five key elements considered essential to effective online learning: social engagement, cognitive engagement, behavioral engagement, collaborative engagement, and emotional engagement. For each of the elements, indicators have been generated to provide illustrative examples of what each element of engagement might look like. Considerable work remains to be completed in order to validate the framework.

Learning and teaching online is complex and we continue to learn how to more effectively support the online learning journeys of students. Educators and researchers will continue to develop tools and strategies to overcome the challenges of our work in the online space. However, there is much we can do to create online learning environments that enhance learning and teaching outcomes, provide opportunities for students to engage online, and to foster connections with each other, instructors, the educational institution, and industry while developing strong disciplinary knowledge and multidisciplinary skills. We believe that the framework that has been designed offers instructors, designers, and researchers who work in the online space a template to guide their work. As the number of students enrolling in online courses in higher education is on the rise, it is important that we explore the nature and the quality of engagement. 


\section{References}

Albion, P. R. (2014). From creation to curation: Evolution of an authentic "assessment for learning” task. In L. Liu, D. Gibson, V. Brown, T. Cavanaugh, J. Lee, C. Maddux, M. Ochoa, M. Ohlson, D. Slykhuis, \& J. Voogt (Eds.), Research highlights in technology and teacher education (pp. 69-78). Waynesville, NC: AACE.

Allen, I., Seaman, J., Poulin, R., \& Straut, T. (2016). Online report card: Tracking online education in the United States. Retrieved from http://onlinelearningsurvey.com/reports/onlinereportcard.pdf

Australian Council for Educational Research. (n.d). Australasian Survey of Student Engagement (AUSSE). Retrieved from https://www.acer.edu.au/ausse

Australian Government Department of Education and Training. (2015). Student Experience Survey (SES). Retrieved from https://www.qilt.edu.au/about-this-site/student-experience$\underline{\text { survey-(ses) }}$

Australian Government Department of Education and Training. (2016a). QiLT: Quality Indicators for Learning and Teaching. Retrieved from https://www.qilt.edu.au/

Australian Government Department of Education and Training. (2016b). Survey of Current Higher Education Students. Retrieved from https://www.qilt.edu.au/about-this-site/studentexperience-survey-(ses)

Billett, S. (2008). Learning through work: Exploring instances of relational interdependencies. International Journal of Educational Research, 47(4), 232-240.

Bowen, S. (2005). Engaged learning: Are we all on the same page. Peer Review, 7(2), 4-7.

Bower, B. L. (2001). Distance education: Facing the faculty challenge. Online Journal of Distance Learning Administration, 4(2). Retrieved from http://www.westga.edu/ distance/ojdla/summer42/bower42.html

Bradley, E. H., Curry, L. A., \& Devers, K. J. (2007). Qualitative data analysis for health services research: Developing taxonomy, themes, and theory. Health Research and Education Trust, 42(4), 1758-1772. doi: 10.1111/j.1475-6773.2006.00684.x

Center for Postsecondary Research, Indiana University School of Education. (2016). National Survey of Student Engagement: Engagement Indicators. Retrieved from http://nsse.indiana.edu/html/engagement indicators.cfm

Chen, P., Lambert, A., \& Guidry, K. (2010). Engaging online learners: The impact of web-based learning technology on college student engagement. Computers \& Education, 54, 1222 1232. doi: 10.1016/j.compedu.2009.11.008

Cheng, K., Liang, J., \& Tsai, C. (2013). University students' online academic help seeking: the role of self-regulation and information commitments. The Internet and Higher Education, 16, 70-77. doi: 10.1016/j.iheduc.2012.02.002

Cleveland-Innes, M., \& Campbell, P. (2012). Emotional presence, learning, and the online learning environment. The International Review of Research in Open and Distributed Learning, 13(4), 269-292. 
Coates, H. (2006). Student engagement in campus-based and online education: University connections. New York, NY: Routledge.

Coates, H. (2007). A model of online and general campus-based student engagement. Assessment and Evaluation in Higher Education, 32(2), 121-141. doi: 10.1080/02602930600801878

Coates, H. (2009). Engaging students for success: Australasian student engagement report: Australian Survey of Student Engagement. Prepared for ACER. Retrieved from http://research.acer.edu.au/cgi/viewcontent.cgi?article=1017\&context=higher_education

Crampton, A., Ragusa, A.T., \& Cavanagh, H. (2012). Cross-discipline investigation of the relationship between academic performance and online resource access by distance education students. Research in Learning Technology, 20. doi: 10.3402/rlt.v20i0.14430

Dennen, V. (2008). Pedagogical lurking: Student engagement in non-posting discussion behaviour. Computers in Human Behaviour, 24(4), 1624-1633. doi: 10.1016/j.chb.2007.06.003

Dixson, M. D. (2015). Measuring student engagement in the online course: The Online Student Engagement Scale (OSE). Online Learning Journal, 19(4). Retrieved from https://onlinelearningconsortium.org/read/online-learning-journal/

Engle, R. A., \& Conant, F. R. (2002). Guiding principles for fostering productive disciplinary engagement: Explaining an emergent argument in a community of learners classroom. Cognition and Instruction, 20(4), 399-483. doi:10.1207/S1532690XCI2004_1

Fleckhammer, L., \& Wise, L.Z. (2010). The role of tutors in facilitating online student engagement. Proceedings ASCILITE, 4-7 December, Sydney.

Fredricks, J. A., Blumenfeld, P. C., \& Paris, A. H. (2004). School engagement: Potential of the concept, state of the evidence. Review of Educational Research, 74(1), 59-109. doi: $10.3102 / 00346543074001059$

Gale, N., Heath, G., Cameron, E., Rashid, S., \& Redwood, S. (2013). Using the framework method for analysis of qualitative data in multi-disciplinary health research. BMC Medical Research Methodology, 13,117. doi: 10.1186/1471-2288-13-117

Garrison, D. R., Anderson, T., \& Archer, W. (2000). Critical inquiry in a text-based environment: Computer conferencing in higher education. Internet and Higher Education, 2(2-3), 87-105. doi:10.1016/S1096-7516(00)00016-6.

Gerhardt, M. (2016). The importance of being... social? Instructor credibility and the millennials. Studies in Higher Education, 41(9), 1533-1547. doi:10.1080/03075079.2014.981516

Gibbs, G. (2014, May 1). Student engagement, the latest buzzword. Times Higher Education. Retrieved from https://www.timeshighereducation.com/news/student-engagement-the-latestbuzzword/2012947.article

Greene, B. A. (2015). Measuring cognitive engagement with self-report scales: Reflections from over 20 years of research. Educational Psychologist, 50(1), 14-30. doi:10.1080/00461520.2014.989230.

Guterman, J. T. (2006). Mastering the art of solution-focused counselling. Alexandria, VA: American Counselling Association 
Hampton, D., \& Pearce, P. F. (2016). Student engagement in online nursing courses. Nurse Educator. Advance online publication. doi:10.1097/NNE.0000000000000275

Handelsman, M. M., Briggs, W. L., Sullivan, N., \& Towler, A. (2005). A measure of college student course engagement. The Journal of Educational Research, 98(3), 184-192. doi:10.3200/JOER.98.3.184-192

Henri, F. (1992). Computer conferencing and content analysis. In A. R. Kaye (Ed.), Collaborative learning through computer conferencing: The Najaden papers (pp. 117-136). Berlin, Germany: SpringerVerlag.

Hickey, D. T., Quick, J. D., \& Shen, X. (2015, March). Formative and summative analyses of disciplinary engagement and learning in a big open online course. In Proceedings of the fifth international conference on learning analytics and knowledge (pp. 310-314). Poughkeepsie, NY: ACM New York.

Higher Education Academy. (2015). UKES: UK Engagement Survey. Retrieved from https://www.heacademy.ac.uk/institutions/surveys/uk-engagement-survey

Kahn, P., Everington, L., Kelm, K., Reid, I., \& Watkins, F. (2017). Understanding student engagement in online learning environments: The role of reflexivity. Education Technology Research and Development, 65, 203-218. doi:10.1007/s11423-016-9484-z

Kift, S. (2004) Organising first year engagement around learning: Formal and informal curriculum intervention, Australian Disability Clearinghouse in Education and Training. Retrieved from http://www.adcet.edu.au/uploads/documents/Sally\%20Kift paper.doc

Knight, E. M. (2013). Aligning the curriculum of the human resources management undergraduate courses at an English-speaking university in the Caribbean with the university's 2012-2017 strategic plan. Global Business and Economics Research Journal, 2(8), 61-86.

Krause, K.-L. (2005). Understanding and promoting student engagement in university learning communities. Retrieved from http://citeseerx.ist.psu.edu/viewdoc/download?doi=10.1.1.659.6304\&rep=rep1\&type=pdf

Krause, K.-L. (2006). Dimensions of student engagement: New opportunities for learning and teaching. Paper presented at the Learning and Teaching Conference, University of Ballarat, July 22.

Krause, K.-L., \& Coates, H. (2008). Students' engagement in first year university. Assessment \& Evaluation in Higher Education, 33(5), 493-505. doi:10.1080/02602930701698892.

Jones, D., Heffernan, A., \& Albion, P. (2015). TPACK as shared practice: Toward a research agenda. In L. Liu \& D. C. Gibson (Eds.), Research highlights in technology and teacher education (pp. 13-20). Waynesville, NC: AACE.

Lawrence, J., Dashwood, A., Burton, L., \& Brown, A. (2013). Anticipating a responsive, relevant and agile institutional pedagogy. In L. Burton, J. Lawrence, A. Dashwood \& A. Brown (Eds.), Producing pedagogy (pp. 156-186). Newcastle upon Tyne, UK: Cambridge Scholars Publishing. 
Lawson, M. A., \& Lawson, H. A. (2013). New conceptual frameworks for student engagement research, policy, and practice. Review of Educational Research, 83(3), 432-479. Retrieved from http://www.jstor.org/stable/24434165

Leech, N. L., \& Onwuegbuzie, A. J. (2007). An array of qualitative analysis tools: A call for data analysis triangulation. School Psychology Quarterly, 22, 557-584. doi:10.1037/1045-3830 .22 .4 .557

Macquarie University Learning and Teaching Centre. (2009). Student engagement principles. Retrieved from https://www.mq.edu.au/lih/pdfs/Engagement_Principles.pdf

Mallon, R. (2013). Naturalistic approaches to social construction. In E. N. Zalta (Ed.), The Stanford encyclopedia of philosophy archive [Online]. Retrieved from http:/plato.stanford.edu/archives/win2014/entries/social-construction-naturalistic/

Meyer, K. (2014). Student engagement in online learning: What works and why. ASHE Higher Education Report, 40(6), 1-14.

Oblinger, D. (2003). Boomers, gen-xers, \& millennials. Educause, July-August, 37-47.

Petty, T., \& Farinde, A. (2013). Investigating student engagement in an online mathematics course through windows into teaching and learning. Journal of Online Learning and Teaching, 9(2), 261-270.

Pittaway, S. (2012). Student and staff engagement: Developing an engagement framework in a faculty of education. Australian Journal of Teacher Education, 37(4), Article 3. doi:10.14221/ajte.2012v37n4.8

Pittaway, S., \& Moss, T. (2014). Initially, we were just names on a computer screen: Designing engagement in online teacher education. Australian Journal of Teacher Education, 39(7), 37-45. doi:10.14221/ajte.2014v39n7.10

Redmond, P. (2014). Reflection as an indicator of cognitive presence. E-Learning and Digital Media, 11(1), 46-58.

Reeve, J., \& Tseng, C.-M. (2011). Agency as a fourth aspect of students' engagement during learning activities. Contemporary Educational Psychology, 36(4), 257-267. doi:10.1016/j.cedpsych.2011.05.002.

Rhodes, C., \& Nevill, A. (2004). Academic and social integration in higher education: A survey of satisfaction and dissatisfaction within a first-year education studies cohort at a new university. Journal of Further and Higher Education, 28(2), 179-193. doi:10.1080/0309877042000206741

Robinson, C. C., \& Hullinger, H. (2008). New benchmarks in higher education: Student engagement in online learning. Journal of Education for Business, 84(2), 101-109. doi:10.3200/JOEB.84.2.101-109

Ryan, G. W., \& Bernard, H. R. (2003). Techniques to identify themes. Field methods, 15(1), 85109. doi:10.1177/1525822X02239569

Scheg, A. (2014). Reforming teacher education for online pedagogy development. Hershey, PA: IGI Global. 
Shea, P., Hayes, S., Smith, S. U., Vickers, J., Bidjerano, T., Pickett, A., . . Jian, S. (2012). Learning presence: Additional research on a new conceptual element within the Community of Inquiry (CoI) framework. The Internet and Higher Education, 15(2), 89-95. doi:10.1016/j.iheduc.2011.08.002.

Sinha, S., Rogat, T. K., Adams-Wiggins, K. R., \& Hmelo-Silver, C. E. (2015). Collaborative group engagement in a computer-supported inquiry learning environment. International Journal of Computer-Supported Collaborative Learning, 10(3), 273-307. doi:10.1007/s11412-015-9218-y.

Sinatra, G., Heddy, B., \& Lombardi, D. (2015). The challenges of defining and measuring student engagement in science. Educational Psychologist, 50(1), 1-13. doi:10.1080/00461520.2014.1002924

Taylor, L., \& Parsons, J. (2011). Improving student engagement. Current Issues in Education, 14(1). Retrieved from http://cie.asu.edu/

Teacher Education Ministerial Advisory Group. (2014). Action now: Classroom ready teachers. Retrieved from https://docs.education.gov.au/system/files/doc/other/action_now classroom_ready teachers accessible.pdf

The Trustees of Indiana University. (2016). NSSE: National Survey of Student Engagement. Available from http://nsse.indiana.edu/

Thompson, N., Miller, N., \& Pomykal Franz, D. (2013). Comparing online and face-to-face learning experiences for non-traditional students. A case study of three online teacher education candidates. The Quarterly Review of Distance Education, 14(4), 233-251.

Vogt, K. (2016). Measuring student engagement using learning management systems (unpublished doctoral dissertation). University of Toronto, Canada. Retrieved from https://tspace.library.utoronto.ca/handle/1807/73213

Weimer, M. (2016, June 22). What does student engagement look like? The Teaching Professor Blog. Retrieved from http://www.facultyfocus.com/articles/teaching-professor-blog/studentengagement-look-

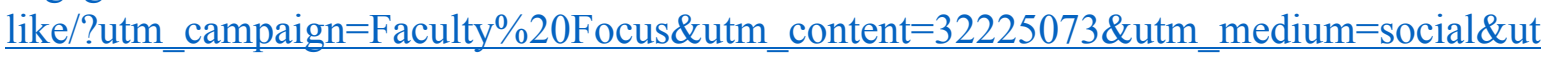
$\underline{\mathrm{m} \text { source }=\text { linkedin }}$

Wright, R., Jones, G., \& D’Alba, A. (2013). Student preferences for rapport-building traits of online instructors. In E-Learn 2013, World Conference on E-Learning in Corporate, Government, Healthcare, and Higher Education, Las Vegas, Nevada.

Young, M. R. (2010). The art and science of fostering engaged learning. Academy of Educational Leadership Journal, 14(S1), 1-18. 